\title{
HÁBITOS ALIMENTARES SAUDÁVEIS NA EDUCAÇÃO INFANTIL
}

\author{
Eda Maria Sousa Matos da Conceição ${ }^{1}$ \\ Jóici Pinheiro da Silva ${ }^{2}$ \\ Joicy Laura da Silva Agripino 3 \\ Karla Freitas Farias Pfingstag ${ }^{4}$ \\ Miriã Dias Ferreira ${ }^{5}$ \\ Rosangela Kovalski da Cruz Lima ${ }^{6}$
}

RESUMO: O objetivo deste artigo é discutir a necessidade de alimentação saudável na primeira infância e propor projetos que introduzam esse tema para crianças na educação infantil. A metodologia utilizada é o estudo bibliográfico e a pedagogia dos projetos no conjunto de duas propostas de projetos a serem aplicados em aula. A alta prevalência de doenças decorrentes de maus hábitos alimentares e sedentarismo entre os jovens vem aumentando a demanda por ações para prevenção dessas doenças e melhoria da qualidade de vida da população. A formação de hábitos alimentares saudáveis e outras atitudes começam na infância, razão pela qual a escola é um local propício para o desenvolvimento de atividades, projetos e ações que levem ao desenvolvimento. frutas. É fundamental que os professores possam desenvolver com os alunos atividades educativas que contribuam para uma alimentação saudável, levando em consideração a idade, a cultura da região e a situação financeira dos envolvidos. As atividades devem contribuir para a compreensão dos alunos e para que possam estender o conteúdo aprendido aos pais, familiares e a comunidade na qual vive. $O$ professor, por meio de projetos pedagógicos criativos, inovadores, interdisciplinares, participativos e em conjunto com a família, pode realizar ações visando à melhoria do conhecimento sobre alimentação, a qualidade de vida a curto $e$ longo prazo e desenvolvendo novos e saudáveis hábitos de alimentação nos alunos e na comunidade.

Palavras chave: Educação alimentar. Educação Infantil. Projetos educativos.

\footnotetext{
I Graduada pela Universidade Federal de Mato Grosso - UFMT, Especialista em Educação Infantil e Anos Iniciais pela Associação Várzea Grandense de Ensino e Cultura - AVEC.

${ }^{2}$ Graduada em Pedagogia pelas Faculdades Integradas de Ariquemes - FIAR.

${ }^{3}$ Graduada em Pedagogia pela Universidade Federal de Mato Grosso - UFMT, Especialista em Docência na Educação Infantil pela Universidade Federal de Mato Grosso - UFMT, Especialista em Educação Infantil e Anos Iniciais pelo Centro Universitário Leonardo da Vinci - UNIASSELVI.

${ }^{4}$ Graduada em Pedagogia pelo Instituto Cuiabano de Educação - ICE, e Especialista em Educação Infantil e Alfabetização pelo Instituto Cuiabano de Educação - ICE.

${ }^{5}$ Graduada em Pedagogia pela Faculdade Invest de Ciências e Tecnologia, Especialista em Educação Especial AEE pela Faculdade Invest de Ciências e Tecnologia.

${ }^{6}$ Formação acadêmica Magistério pela Escola de 2o Grau Darwin Monteiro da Silva.
} 
ABSTRACT: The purpose of this article is to discuss the need for healthy eating in early childhood and to propose projects that introduce this topic to children in early childhood education. The methodology used is the bibliographic study and the pedagogy of the projects in the set of two project proposals to be applied in class. The high prevalence of diseases resulting from poor eating habits and physical inactivity among young people has increased the demand for actions to prevent these diseases and improve the population's quality of life. The formation of healthy eating habits and other attitudes begin in childhood, which is why the school is a favorable place for the development of activities, projects and actions that lead to development. fruits. It is essential that teachers can develop educational activities with students that contribute to a healthy diet, taking into account the age, culture of the region and the financial situation of those involved. Activities should contribute to students' understanding and so that they can extend the content learned to parents, family members and the community in which they live. The teacher, through creative, innovative, interdisciplinary, participatory pedagogical projects and together with the family, can carry out actions aimed at improving knowledge about food, quality of life in the short and long term and developing new and healthy eating habits. in students and in the community.

Keywords: Food education. Child education. Educational projects.

\section{INTRODUÇÃO}

O número de doenças causadas pelos maus hábitos de vida, principalmente relativos à alimentação e falta de atividade física é cada vez maior, por exemplo as Doenças Crônicas Não Transmissíveis (DCNT) que eram encontradas principalmente em idosos, atualmente atingem pessoas de uma faixa etária cada vez menor. Dentre as mais comuns temos: diabete, hipertensão, obesidade, hiperlipidemias e suas complicações como as doenças cardiovasculares, renais, oculares e cerebrais. Os maus hábitos alimentares na infância, resultam na obesidade infantil, produzindo problemas de saúde imediatos e também à longo prazo. A quantidade e qualidade da alimentação sofreu alterações ao longo dos anos, sendo mais comum consumir de alimentos processados, congelados, ricos em sódio, açúcares e gorduras saturadas - alimentos de alto valor energético e baixo valor nutricional. A alimentação desequilibrada contribuir para o aparecimento de desnutrições como anemias e hipovitaminoses. Diversos fatores colaboram na formação dos hábitos alimentares nas crianças como: valores socioculturais, imagem corporal, necessidades fisiológicas e saúde individual, preferências, convivências sociais (hábitos familiares e de amigos), situação financeira familiar, acesso a alimentos fora de casa e de alimentos semi- 
preparados, influência exercida pela mídia, entre outros. São fatores determinantes dos extremos da alimentação, uma vez que as crianças podem ser classificadas como obesas ou até mesmo aquelas que sofrem de anorexia.

A escola tem participação no processo de educação alimentar do aluno. É na escola que as crianças e jovens passam grande parte do seu dia, convivem com pessoas da mesma faixa etária e adultos nos quais se espelham e tem confiança. Diante do exposto, ações de educação alimentar e nutricional com alunos da educação infantil podem ocasionar modificações nas escolhas alimentares e melhorar a qualidade de vida da criança e do futuro adulto.

Os Parâmetros Curriculares Nacionais de Saúde (PCN) (BRASIL, 2016), mesmo que a educação em saúde seja responsabilidade de muitas outras instâncias, em especial dos próprios serviços de saúde, a escola ainda é a instituição que, pode se transformar num espaço de promoção da saúde. Muitas iniciativas locais vêm sendo tomadas para implementar a educação para a Saúde, e o desafio, no momento, é construir referenciais que contemplem esse direito para todos os alunos.

Existem diversos projetos, leis, resoluções, iniciativas públicas e privadas relativas a alimentação saudável na infância. Percebe-se uma preocupação em oferecer ações educativas e garantir a oferta de alimentos em quantidade e qualidade adequadas. Assim sendo, é importante que o professor esteja capacitado no desenvolvimento de práticas educativas com os alunos contribuindo para hábitos alimentares saudáveis, levando em conta a faixa etária, a cultura da região, a situação financeira dos envolvidos. As atividades devem permitir para a compreensão dos alunos e para que possam estender o conteúdo aprendido aos pais, familiares e a todos no ambiente no qual vive.

O objetivo geral deste artigo é discutir acerca da necessidade de hábitos alimentares saudáveis na infância e propor projetos que apresentem o tema para os alunos da Educação Infantil.

\section{DESENVOLVIMENTO}

A preocupação com estilos de vida saudáveis é resultado de um número crescente de doenças na infância e na idade adulta, causadas pela má alimentação. "As 
transformações ocorridas no Brasil, relacionadas à crescente modernização e urbanização, estão associadas a mudanças no estilo de vida e nos hábitos alimentares da população, sendo estas mudanças consideradas como favorecedoras para o desenvolvimento das doenças crônicas não-transmissíveis" (SCHMITZ, 2016, p. I).

A obesidade é considerada uma epidemia e um problema de saúde pública. A obesidade afeta todas as idades e todas as esferas da vida, superando até doenças que prejudicam seriamente a saúde, como desnutrição e doenças infecciosas. A maior prevalência era em países desenvolvidos mas, atualmente, é crescente o número de casos em países em desenvolvimento como o Brasil. Segundo dados do Portal Brasil, 7,3\% das crianças até 5 anos estão acima do peso.

[...] entre 5 e 9 anos, o percentual de crianças com excesso de peso chega a 33,5\%. $\mathrm{Na}$ adolescência, o quantitativo é de $20,5 \%$. Além disso, os dados mostram que o estado nutricional na primeira infância repercute na vida adulta. Nesse contexto, a prevalência de excesso de peso em adultos tem crescido nos últimos anos. Em 2012, metade da população adulta estava com excesso de peso, sendo $17,2 \%$, com obesidade (BRASIL SUPERA, 2016, p. I).

Podemos perceber então que as políticas públicas para a erradicação do baixo peso

infantil estão surtindo efeito, mas é preocupante o crescimento da obesidade decorrente de um melhor nível econômico da população.

Abrantes et. al. (2016) afirma que a obesidade está relaciona com hipertensão arterial, doença cardíaca, oesteoartrite, diabetes tipo 2 e alguns tipos de câncer, e seu impacto é mais pronunciado na morbidade do que na mortalidade. Pessoas obesas, especialmente crianças e adolescentes, frequentemente apresentam baixa autoestima, afetando a performance escolar e os relacionamentos. Existem evidências científicas que revela que a aterosclerose e a hipertensão arterial são processos patológicos iniciados na infância, e nesta faixa etária são formados os hábitos alimentares e de atividade física. $\mathrm{O}$ Guia alimentar para a população brasileira aponta que:

A alimentação, quando adequada e variada, previne as deficiências nutricionais e protege contra as doenças infecciosas, porque é rica em nutrientes que podem melhorar a função imunológica. Pessoas bem alimentadas são mais resistentes às infecções. [...] Essa proteção é devida a três fatores interrelacionados: I) o consumo de uma diversidade de nutrientes que protegem e mantêm o funcionamento adequado do organismo; 2) a reduzida quantidade de gorduras saturadas, gorduras totais, açúcares, sal e álcool, componentes relacionados ao aumento de risco de DCNT; 3) a baixa concentração energética que previne o 
excesso de peso e a obesidade, que, por sua vez, aumentam o risco de outras doenças crônicas não-transmissíveis (BRASILc, 2016, p. 42).

Diante dessa realidade é de suma importância que a escola se coloque na linha de frente ao combate aos maus hábitos de alimentação das crianças e adolescentes. Existem leis, resoluções e políticas públicas em âmbito federal e estadual que amparam os profissionais em defesa de uma alimentação saudável dentro das escolas. A Resolução 26 de 17 de junho de 2013, que dispõe sobre o atendimento da alimentação escolar aos alunos da educação básica no âmbito do Programa Nacional de Alimentação Escolar (PNAE). Entre as diretrizes deste programa estão a inclusão da educação alimentar e nutricional no processo de ensino e aprendizagem, que perpassa pelo currículo escolar, abordando o tema alimentação e nutrição e o desenvolvimento de práticas saudáveis de vida na perspectiva da segurança alimentar e nutricional; o direito à alimentação escolar, objetivando a segurança alimentar e nutricional dos alunos, com acesso de forma igualitária, respeitando as diferenças biológicas entre idades e condições de saúde dos alunos que necessitem de atenção específica e aqueles que se encontrem em vulnerabilidade social.

Art. $3^{\circ}$ O PNAE tem por objetivo contribuir para o crescimento e o desenvolvimento biopsicossocial, a aprendizagem, o rendimento escolar e a formação de práticas alimentares saudáveis dos alunos, por meio de ações de educação alimentar e nutricional e da oferta de refeições que cubram as suas necessidades nutricionais durante o período letivo (BRASILa, 2016).

$\mathrm{O}$ art. I4, ressalta a necessidade de se construir cardápios "com utilização de gêneros alimentícios básicos, de modo a respeitar as referências nutricionais, os hábitos alimentares, a cultura alimentar da localidade e pautar-se na sustentabilidade, sazonalidade e diversificação agrícola da região e na alimentação saudável e adequada" (BRASILa, 2016).

Em Minas Gerais por exemplo, temos a Resolução SEE nº 1.5II, de 26 de fevereiro de 20ı, que orienta a aplicação da Lei no 18.372/2009 no âmbito das escolas do sistema estadual de ensino. No seu art. 2, a Resolução aponta que:

Fica vedada, nos espaços das escolas estaduais, a comercialização de lanches e bebidas contendo os produtos e/ou preparações, industrializados ou não, que contenham altos teores de calorias, gordura saturada, gordura trans, açúcar livre, sal, teor alcoólico e baixo teor nutricional, tais como: a) Frituras: batatas, biscoitos, bolinhos, coxinhas, enroladinhos recheados, espetinhos, pastéis, quibes e frituras em geral; b) salgados e doces com massa folhada; c) biscoitos: recheados, com cobertura, tipo wafer, biscoitos salgados e outros com alto teor de gorduras e calorias; d) doces: balas, pastilhas, pirulitos, chocolates e bombons, 
suspiros, mariamole, sorvetes de massa, picolés de massa com cobertura, chupchup, algodão doce, gomas de mascar e guloseimas em geral; e) molhos calóricos: catchup, maionese, mostarda, molhos a base de maionese e outros com alto teor de gorduras e calorias; f) bebidas artificiais: refrigerante comum, light e zero, refrescos artificiais, bebidas alcoólicas, energéticos e outras bebidas similares; g) salgadinhos e pipocas industrializadas; h) alimentos apresunt ados e embutidos; i) sanduíches e pizzas que tragam em sua composição ingredientes como bacon, batata palha, maionese e molhos gordurosos e calóricos, mortadelas, ovos fritos, queijos gordurosos e outros ingredientes e embutidos ricos em gorduras e calorias. Parágrafo único. As restrições mencionadas também se aplicam aos produtos obtidos por doações (MINAS GERAIS, 2016).

E ainda reforça no art. 4ํㅡㄹ parágrafo único que "a escola deverá desenvolver atividades que reforcem hábitos de alimentação saudável” (MINAS GERAIS, 2016), ou seja, é papel da escola educar as crianças para hábitos de alimentação mais saudáveis, por isso as escolas estaduais mineiras não têm mais barzinhos para venda de produtos as crianças e disponibilizam apenas a merenda regular que deve seguir as diretrizes dessa Resolução.

Como foco desse artigo é a alimentação de crianças, também abordarmos as instruções que o Referencial Curricular Nacional para Educação Infantil (RCNEI) trazem para esse nível da educação.

As instituições que atendem meio período, nas quais as crianças apenas fazem pequenos lanches ou merenda, precisam também preocupar-se com as questões nutricionais e sempre que possível respeitar práticas sociais e culturais de cada criança. Oferecer apenas merendas industrializadas ou lanches compostos por salgadinhos, bolachas, balas e chocolates não atendem a necessidade do organismo de ingerir frutas e sucos naturais (BRASILb, 2016, p. 54).

A escola precisa organizar espaços e momentos apropriados para o lanche, com cardápios balanceados que permitam se alimentar "de acordo com as diversas práticas sociais em torno da alimentação, sempre permeadas pelo prazer e pela afetividade, permitindo que as crianças conversem entre si” (BRASILb, 20r6, p. 55). A escola deve "possibilitar às crianças oportunidades que propiciem o acesso e conhecimento sobre os diversos alimentos, o desenvolvimento de habilidades para escolher sua alimentação, servir-se e alimentar-se com segurança, prazer e independência" (BRASILb, 2016, p. 55), sem se esquecer da necessidade de formar parceria com a família para que os ensinamentos alimentares adquiridos na escola sejam seguidos fora dela. 
O professor deve ter conhecimento acerca da alimentação saudável para que, junto com outros profissionais, possa planejar e implantar medidas de inclusão de hábitos alimentares saudáveis no ambiente escolar. Segundo Barreto et al. (2016, p. 311-312), quando se aplica programas alimentares:

[...] em idades mais precoces têm maiores chances de êxito, uma vez que a vida intra-uterina e a infância, principalmente o período pré-escolar, são momentos críticos, durante os quais a regulação do balanço energético é programada. Existem evidências de que o desenvolvimento do sobrepeso em fase precoce da vida pode se tornar em importante fator de risco para o aparecimento de obesidade posteriormente.

Por sua vez Schmitz (2006), aponta que o ambiente escolar é o mais propício:

[...] à aplicação de programas de educação em saúde em larga escala, incluindo programas de educação nutricional. Estes devem consistir em processos ativos, lúdicos e interativos, que favoreçam mudanças de atitudes e das práticas alimentares. Nesse ambiente, o educador deve ser um facilitador, que saiba utilizar várias estratégias de ensino, contribuindo para a melhoria da alimentação das crianças. Para tal, deve também possuir conhecimentos e habilidades sobre promoção da alimentação saudável, procurando incorporálos ao seu fazer pedagógico. Esses conhecimentos devem ser construídos de forma transversal no ambiente escolar, garantindo a sustentabilidade das ações dentro e fora de sala de aula (SCHMITZ, 2or6, p. I).

Além de ter conhecimento na área de alimentação saudável, fazem-se necessárias estratégias pedagógicas e ações interdisciplinares, numa parceria entre escola, pais e profissionais da saúde para a promoção de uma educação alimentar adequada. A escola pode desenvolver diversas estratégias para a educação alimentar e nutricional dos alunos da educação infantil, apontando caminhos, fazendo discussões e possibilitando aos alunos a oportunidade de conhecerem e consumirem alimentos mais saudáveis e variados saindo do circuito da propaganda e dos alimentos industrializados.

\section{2.r A pedagogia de projeto}

A pedagogia baseada em projetos é um novo método de ensino que integra uma variedade de conteúdos especializados e fontes de mídia. Nessa proposta, os professores deixam de ensinar por meio da transmissão de informações e criam situações de aprendizagem, permitindo que os alunos aprendam no processo de produção, dúvida, pesquisa. Os professores são mediadores que ajudam os alunos a encontrar significado no que aprendem por meio de situações criadas. 
Segundo Prado (2009) para fazer a mediação pedagógica, o professor deve acompanhar o processo de aprendizagem do aluno, ou seja, entender seu caminho, seu universo cognitivo e afetivo, bem como sua cultura, história e contexto de vida. Além disso, é fundamental que o educador tenha clareza da sua intencionalidade pedagógica para saber intervir no processo de aprendizagem, garantindo que os conceitos utilizados, intuitivamente ou não, na realização do projeto sejam compreendidos, sistematizados e formalizados pela turma.

\begin{abstract}
O trabalho por projetos requer mudanças na concepção de ensino e aprendizagem e, consequentemente, na postura do professor. Hernández (1988, p. 49) enfatiza que o trabalho por projeto "não deve ser visto como uma opção puramente metodológica, mas como uma maneira de repensar a função da escola". Essa compreensão é fundamental, porque aqueles que buscam apenas conhecer os procedimentos, os métodos para desenvolver projetos, acabam se frustrando, pois não existe um modelo ideal pronto e acabado que dê conta da complexidade que envolve a realidade de sala de aula, do contexto escolar (PRADO, 20I6, p. 3).
\end{abstract}

As crianças são muito curiosas, gostam de ajudar os adultos nas tarefas de casa, nas preparações culinárias, etc. Os pais e professores quando as convidam para fazer pequenas tarefas e quando as desenvolvem se sentem mais capazes, confiantes e alegres. A criança aprende observando e participando das atividades dos adultos e das crianças mais velhas. Dessa forma a escola pode mediar projetos que envolvam os pais, os alunos e toda comunidade escolar, tendo as crianças como protagonistas das ações desenvolvidas.

A pedagogia de projetos deve permitir que o aluno aprenda-fazendo e reconheça a própria autoria naquilo que produz por meio de questões de investigação que lhe impulsionam a contextualizar conceitos já conhecidos e descobrir outros que emergem durante o desenvolvimento do projeto. Nessa situação de aprendizagem, o aluno precisa selecionar informações significativas, tomar decisões, trabalhar em grupo, gerenciar confronto de ideias, enfim, desenvolver competências interpessoais para aprender de forma colaborativa com seus pares (PRADO, 2016, p. 7).

$\mathrm{O}$ aprender-fazendo passa pelo uso de múltiplos gêneros textuais, TICs (Tecnologias da Informação e Comunicação) assim como metodologias variadas como atividades lúdicas e em grupo que permitam ao aluno desenvolver seu potencial criativo, questionador e construir suas habilidades e competências de forma mais prazerosa e dinâmica. 


\title{
2.3 Propostas de projetos
}

\section{PROJETO I: ALIMENTAÇÃO SAUDÁVEL}

Este projeto pode ser realizado com alunos da Educação Infantil, durante o período letivo. Com o desenvolvimento do projeto os alunos são envolvidos com as disciplinas de Artes, Matemática, Português e Ciências. Utilizadando material, utensílios e ingredientes para a oficina culinária.

\section{INTRODUÇÃO}

A educação alimentar e nutricional é um tema que não deve ser ignorado no planejamento do professor da Educação Infantil, pois:

\begin{abstract}
A fase da infância apresenta importantes aspectos para a formação de hábitos e práticas comportamentais em geral, e especificamente alimentares. Nessa perspectiva, a escola é um espaço privilegiado para a construção e a consolidação de práticas alimentares saudáveis em crianças, pois é um ambiente no qual atividades voltadas à educação em saúde podem apresentar grande repercussão (YOKOTA, 2016, p. 39).
\end{abstract}

A promoção de hábitos alimentares saudáveis é a estratégia principal e deve ser trabalhada por meio de vários outros conteúdos, permitindo que a criança desenvolva um novo olhar sobre o que é alimentar-se de forma saudável e prazerosa.

Em geral as crianças têm resistência em comer determinados alimentos apenas pelo seu aspecto ou cor. Eles sequer querem experimentar. Pensando nisso montamos o projeto a partir da beterraba, alimento que os alunos não são muito afeitos, mas que se comerem sem saber (como um ingrediente secreto), podem começar a gostar.

Para tanto o professor poderá montar um projeto no qual as crianças tenham contato com a disciplina de Matemática, se atentando as quantidades dos ingredientes no desenvolver das receitas, das formas geométricas dos alimentos e da preparação. A disciplina de Português estará presente, com a leitura de textos, imagens e na comunicação.

Em Arte, as crianças vão produzir pratos bem enfeitados, com harmonia de cores e sabores, verdadeiras "obras de arte". Todos os sentidos do corpo serão trabalhados, olfato, visão, paladar, audição, tato, o que envolve a disciplina de Ciências, bem como o estudo das propriedades nutricionais. Além das informações nutricionais e da 
interdisciplinaridade, o aluno aprende a trabalhar em equipe, dividir tarefas, respeitar a opinião e as sugestões do colega.

As atividades com alimentos promovem o desenvolvimento da criança e tornam a pedagogia de projetos uma metodologia que permitirá ao aluno adquirir conhecimentos por meio da experimentação, da pesquisa e do questionamento da sua realidade.

\section{OBJETIVO GERAL}

Melhorar os hábitos alimentares de crianças, por meio da apresentação, preparo e degustação de receitas saudáveis.

\section{Desenvolvimento}

\section{Semana: Degustação dos lanches}

Como sugestão pode ser realizado um piquenique com os alunos. Todos os lanches e utensílios é providenciado pelo professor. O mesmo pode ser realizado durante o horário de aula, porém em outro ambiente, fora da sala de aula mais dentro da escola. O nome dos lanches é modificado para a primeira apresentação. É oferecido às crianças Suco de Uva e Pizza Colorida, e informados que foi utilizado um ingrediente secreto que será revelado no próximo encontro. Todos os ingredientes utilizados para a pizza serão saudáveis, assim como para o suco.

\section{Semana: Revelação do ingrediente}

Neste encontro o professor leva uma caixa bem decorada, cheia de objetos dentro para a apresentação aos alunos. O primeiro objeto a ser tirado será o ingrediente secreto, a beterraba com folhas para mostrar como a beterraba cresce no solo. $O$ professor explica brevemente suas características principais, como cor, sabor, textura, outras aplicações como, por exemplo, a produção de açúcar, como consumir, onde podemos adquirir o alimento, entre outros. Aponta que a beterraba possui muitas vitaminas que são importantes para que a criança não tenha anemia, fique doente e tenha que tomar remédios. Perguntar se em casa o aluno come beterraba e outros legumes e verduras. 
Posteriormente de dentro da caixa ele tira figuras que exemplifica as propriedades nutricionais e os benefícios para a saúde. Apontando que o suco e a pizza que comeram na semana anterior tinham, entre outros ingredientes, beterraba como o ingrediente secreto.

Em seguida o professor mostra outros pratos que podem conter o alimento. Em todos os momentos os alunos envolvidos, ficando livres para perguntas e comentários.

Cantar com as crianças uma versão da música Borboletinha: "Borboletinha tá na cozinha/fazendo suco de beterraba para a madrinha. Poti, poti/perna de pau/olho de vidro/e nariz de pica-pau pau pau.” Fazer atividade para casa com a letra B de beterraba e um desenho para colorir.

\section{$3^{\text {a Semana: Oficina culinária }}$}

Neste dia os alunos ajudam no preparo dos mesmos lanches oferecidos no primeiro encontro mais outros apresentados pelo professor no segundo encontro. Dessa vez os pais ajudam no preparo e na degustação dos pratos. Os grupos formados pelos pais e alunos, cada grupo fica responsável por uma preparação. Os pais e os alunos colaboram com os ingredientes e utensílios utilizados.

O espaço para o preparo e a realização de toda a atividade é a cantina e o refeitório da escola. O ambiente decorado com informações nutricionais e figuras referentes à beterraba. Haverá também referência a outros alimentos saudáveis que compõe as receitas. Para encerrar cada equipe apresenta seu prato e, no final das apresentações, monta-se uma mesa e todos saboreiam os pratos.

A turma pode ser dividida em dois grupos de pais e filhos. O grupo um fica responsável pela preparação do suco de "uva", seguindo a receita abaixo ou outra da preferência dos pais:

Ingredientes do suco: I beterraba sem casca cortada em pedaços; I limão galego sem casca, sementes e filamento branco; mel a gosto (se necessário); i e I/2 copo de água. Depois de limpos todos os ingredientes devem ser batidos no liquidificador, dependendo do ingrediente agregado à beterraba deve-se coar antes de beber.

O limão pode ser substituído por outros ingredientes como: abacaxi, cenoura, maçã, melancia, laranja, etc. Deve-se usar frutas da estação por ser mais baratas e nutritivas. 
É sugerido que cada grupo responsável pelo suco faça sucos de "uva" com sabores diferenciados e que os alunos escolham o que acharem mais gostoso. Pode-se, inclusive, ao final do preparo do suco e da pizza fazer um concurso para eleger o suco e o recheio mais gostoso.

O grupo 2 fica responsável pela pizza colorida. O recheio de cada pizza pode ser diferente, desde que use alimentos naturais e se evite alimentos industrializados, com muito sal ou gordura.

Ingredientes da massa de pizza colorida

Para o Purê de beterraba: I beterraba grande; I/2 copo de água. Cozinhe a beterraba com casca e bata no liquidificador para formar um purê.

Para a massa: I xícara de chá de leite; 2 xícaras de chá de farinha de trigo; I colher de sopa de fermento biológico; 2 colheres de sopa de óleo de soja; I pitada de sal. Numa tigela, misture todos os ingredientes da massa e o purê de beterraba até obter uma mistura homogênea. Abra a massa e asse em forno previamente aquecido por 5 minutos. Disponha os ingredientes do recheio e leve novamente ao forno por 5 minutos.

Recheio: podem ser feitos vários recheios diferentes - tradicionais (com cogumelos, tomates, queijos, carnes diversas) ou vegetarianos (espinafre, cenoura, palmito, pimentão, etc.).

Durante essa atividade o professor deve reforçar a importância de uma alimentação nutritiva para que a criança cresça saudável e seja um adulto com saúde melhor.

\section{VARIAÇÕES}

Em uma variante da atividade os alunos podem colher junto aos pais outras receitas com beterraba e na semana da Oficina fazer receitas como: brigadeiro de beterraba, espaguete de beterraba, nhoque de beterraba, panqueca de beterraba, sorvete de beterraba , etc. Outra variação pode ser no ingrediente secreto. Pode-se utilizar outros legumes e verduras naturais para dar cor e sabor aos alimentos como espinafre ou couve (verde), cenoura ou abobora (laranja), etc.

\section{AVALIAÇÃO}


A avaliação ocorre através da participação, interesse pelas atividades, trabalho em equipe, envolvimento com o projeto e a mudança de hábitos alimentares.

\section{CRONOGRAMA}

O projeto contempla três semanas de atividades, podendo se estender mais de acordo com o interesse dos alunos.

\section{REFERÊNCIA}

YOKOTA, Renata Tiene de Carvalho et. al. Projeto "a escola promovendo hábitos alimentares saudáveis": comparação de duas estratégias de educação nutricional no Distrito Federal, Brasil. Disponível em: Acesso em: 02 set. 2016.

\section{PROJETO 2: SER SAUDÁVEL}

Este projeto será realizado com alunos da Educação Infantil, durante o período letivo. Com o desenvolvimento do projeto os alunos envolvem as disciplinas de Artes, Matemática, Português e Ciências. Será utilizado: vídeo, material impresso, recorte de revistas, tapete feito de não tecido e fita adesiva, ficha com os conteúdos do jogo e um dado.

\section{INTRODUÇÃO}

Os alunos da educação infantil são curiosos e se dispersam facilmente. Dessa forma, prender sua atenção não é tarefa fácil. Este jogo tem a missão de ensinar de maneira prazerosa sobre alimentação e hábitos de vida saudáveis permitindo que os alunos adquiram conhecimentos de forma criativa e lúdica.

\footnotetext{
Vale considerar que o jogo como instrumento de aprendizagem é um recurso de extremo interesse aos educadores, uma vez que sua importância está diretamente ligada ao desenvolvimento do ser humano em uma perspectiva social, criativa, afetiva, histórica e cultural. Levando-se em conta isso, é de extrema importância que os profissionais que trabalham com crianças devam se interessar e buscar conhecimento sobre a temática, permitindo assim um melhor direcionamento no seu trabalho pedagógico (ALVES, 2016, p. 283).
} 
Este jogo é fácil e estimula a competividade, o que o torna mais interessante. Para o sucesso desse projeto é necessário o domínio do conteúdo pelo professor. Por mais que contenha ficha de instrução, o jogo mistura brincadeira com muita informação. Esta por sua vez deve ser feita de forma natural, por se tratar de um tema cotidiano.

Para que as atividades de educação em saúde sejam bem desenvolvidas na escola, os professores, atores chaves desse processo, que atuam como facilitadores da articulação entre teoria e situação prática, precisam estar bem informados e orientados sobre o tema, para reconhecer a importância de sua atuação na área de saúde. O treinamento, a sensibilização e a motivação dos professores nestas atividades podem ser mediados por profissional da área da saúde (YOKOTA, 2016, p. 39).

A formação das preferências alimentares faz parte do aprendizado, e a criança tende a imitar o que os outros fazem, sejam pessoas da família, outras crianças, figuras de referência que incluem pais, professores, diretores.

A fase da infância apresenta importantes aspectos para a formação de hábitos e práticas comportamentais em geral, e especificamente alimentares. Inserida no contexto familiar, a criança começa a formar e internalizar os padrões de comportamento alimentar, em termos de escolha e quantidade de alimentos, horário e ambiente das refeições. Trata-se de um processo que se inicia nesta fase e se estende por todas as demais fases do ciclo de vida (YOKOTA, 2016, p.39).

Portanto a interação de toda a comunidade escolar contribui de modo positivo para o sucesso do projeto e a consequente mudança dos hábitos alimentares e saudáveis dos escolares.

\section{OBJETIVO GERAL}

Incentivar hábitos saudáveis de crianças, através do jogo educativo, com temas relacionados à alimentação e atividade física.

\section{DESENVOLVIMENTO}

I Etapa: Roda de conversa - Apresentação do vídeo Se alimentar bem, é bom! Disponível em https://www.youtube.com/watch?v=B83EFwoQfk4.

Discutir com os alunos sobre o que eles aprenderam com o vídeo: a importância de uma alimentação variada que envolva todos os tipos de alimentos proteínas, carboidratos, frutas e verduras, gorduras. Perguntar sobre o que comem em casa, quais comidas eles mais gostam, se eles fazem exercícios. Ao fazer essa roda de conversa o 
professor está levantando um perfil geral da turma e introduzindo a questão da boa alimentação (perguntando se eles acham que tudo que comem é saudável e faz bem a sua saúde, etc.) e da necessidade do exercício físico (perguntando se eles sabem quais os benefícios que o exercício traz para a saúde, etc.).

Construir uma tarefa para casa na qual os alunos devem identificar o que é saudável na sua alimentação. Essa tarefa pode ser uma pesquisa com os pais ou uma folha de exercícios.

\section{2- etapa: Construção do tapete}

Incentivar as crianças a construir um tapete para jogarem o jogo da criança saudável e feliz.

Materiais: 3 metros de não-tecido; Folhas A4; Recorte de revistas; Fita adesiva branca; I dado de seis lados que pode ser construído de material reciclado.

Modo de fazer: Divida o não tecido em partes de $30 \mathrm{~cm}$ e passe a fita adesiva no sentido horizontal separando os espaços. Em cada espaço coloca-se uma folha $\mathrm{A}_{4}$, com os dizeres abaixo, que podem ser escritas com pincel ou impressas:

I. Comer na mesa Inclusão de hábitos alimentares saudáveis na educação infantil
2. Mastigar
3. Frutas e verduras
4. Sucos naturais
5. Refeições saudáveis
6. Atividade física
7. Guloseimas
8. Sedentarismo
9. Refrigerante
Io. Tomar água

As palavras chaves que compõem a brincadeira podem ser alteradas de acordo com a necessidade, mais é importante reforçar as atitudes positivas e desencorajar as atitudes negativas. A ficha ajuda a nortear a brincadeira, mas é interessante que o condutor da atividade não fique preso a ela, abrindo espaço para a participação dos alunos e outras observações. 
Fichas:

I. Comer na mesa: É muito importante comer na mesa, não podemos comer assistindo televisão.

2. Mastigar: Devemos comer devagar, mastigando bem os alimentos.

3. Frutas e verduras: São muito importantes para a nossa saúde. Fornece um monte de vitaminas que fazem o cabelo ficar bonito, a pele macia, ficarmos mais fortes, animados, inteligentes.

4. Sucos naturais: É muito importante os sucos feitos da fruta. Os de saquinho e caixinha não são saudáveis.

5. Refeições saudáveis: É importante fazer pelo menos 5 refeições por dia. Comer arroz, feijão, verduras e frutas, carnes, leite, pão etc.

6. Atividade física: Temos que fazer atividade física: brincar, jogar bola, andar de bicicleta, caminhar com o papai e a mamãe, passear com o cachorrinho, etc. Não pode ficar só no vídeo-game, no computador, no celular.

7. Guloseimas: Comer muita bala, chiclete, chocolate, salgadinho, faz a gente ficar doente. Pode dar diabete, pressão alta, cárie, etc. Não se esqueça que todas as refeições devem ser saudáveis, por isso volte a casa 5 .

8. Sedentarismo: Não pode ser sedentário, tem que se movimentar. Como castigo volte a casa 6.

9. Refrigerantes: Faz muito mal á saúde, deve ser usado com moderação. Prefira os sucos naturais e, portanto, volte a casa 4 .

Io. Tomar água: É muito importante tomar água, sem ela a gente não vive! Parabéns, você ganhou!

A parte da montagem do tapete é de responsabilidade do professor. Cabe aos alunos, como tarefa de casa, recortar de revistas figuras que representam as palavras chaves, eles podem colar essas figuras nos números e no não tecido. Os alunos também podem montar o dado grande a partir de uma caixa com os números de I a 6 ou com imagens de I a 6.

Modo de brincar:

Os alunos são separados em duas equipes. Se forem muitos integrantes escolhe-se dois representantes. Os dois jogadores se posicionam um à esquerda e outro à direita; um deles joga o dado e avança até o número sorteado. O professor faz uma breve observação 
referente ao tema sorteado (utilizando as fichas) e aplica a consequência se houver. Após são feitos os comentários, repete-se a instrução anterior com o segundo jogador. $\mathrm{O}$ jogador fica parado no espaço referente ao número sorteado, joga-se o dado novamente e avança de casa, semelhante a um jogo de tabuleiro. O ganhador será aquele que conseguir chegar ao número Io. Se houver tempo trocam-se os participantes e recomeça o jogo.

As observações devem ser feitas respeitando a idade da criança, a situação econômica, tradições, costumes entre outros. Cabe ao professor enfatizar as ações saudáveis, reforçandoas.

\section{VARIAÇÕES}

Com esse mesmo jogo, o professor interage com a comunidade escolar através de uma gincana. O jogo proposto pode ter o formato reto (como uma amarelinha) ou em formas diferentes como um caracol ou uma cobra.

O professor pode montar outros tipos de jogos com alimentação saudável como: a) Jogo da cestinha: em uma cesta os alunos devem colocar apenas os alimentos saudáveis (que podem ser reais ou imagens - escolhidos entre diversas opções) e depois explicar a escolha desse ou aquele alimento. b) Bingo de alimentos: cartelas diferenciadas para cada aluno com imagens de alimentos, sortear alguns e discutir se o alimento é saudável ou não. c) Roleta dos alimentos: em uma roleta, coloca-se imagens de alimentos variados, quando a roleta parar em um alimento a criança deve dizer seu nome e se ele é saudável ou não.

Existem vários jogos que se podem ser montados em sala e trabalhados com os alunos, cumprindo o objetivo de levar as crianças a refletir sobre quais são os hábitos alimentares saudáveis que ela deve ter. Cabe a professor uitilizar o que melhor se adaptar aos seus alunos.

\section{AVALIAÇÃO}

A avaliação ocorre através da participação, interesse pela atividade, respeito aso colegas, envolvimento com o projeto e a mudança de hábitos alimentares e de atividade física. 


\section{CRONOGRAMA}

O projeto pode ser realizado em duas etapas em três dias ou mais, dependendo do interesse dos alunos.

\section{REFERÊNCIAS}

ALVES, Luciana et. al. O jogo como recurso de aprendizagem. Rev. Psicopedagogia 2010; 27(83): 282-7. Disponível em http://pepsic.bvsalud.org/pdf/psicoped/v27n83/13.pdf. Acesso em 17/02/2022.

YOKOTA, Renata Tiene de Carvalho et. al. Projeto "a escola promovendo hábitos alimentares saudáveis": comparação de duas estratégias de educação nutricional no Distrito Federal, Brasil. Rev. Nutr., Campinas, 23(I):37-47, jan./fev., 2010. Disponível em https://www.scielo.br. Acesso em i7/02/2022.

\section{CONCLUSÃO}

Nos primeiros anos de vida que se formam os hábitos alimentares da criança, que podem mudar ao longo do tempo, pois são influenciados pelo meio em que o aluno vive. Os professores, famílias e escolas desempenham um papel importante na promoção e formação de hábitos saudáveis, pois as crianças passam a maior parte do tempo na escola. Eles têm o professor e a família como espelho, por isso ações e projetos voltados para a educação culinária e atividades físicas na escola são um dos alicerces para a construção de comportamentos saudáveis de alimentação e bebida, melhorarando a qualidade de vida.

A crescente modernização e a necessidade de ambos os pais trabalharem para sustentar a família faz com que passem cada vez mais tempo fora de casa. A correria do dia a dia também aumenta o consumo de fast food congelado, pronto para comer, rico em calorias e baixo valor nutricional. Esses hábitos nada saudáveis podem ser os precursores de doenças que a criança desenvolverá ao se tornar adulta. A parceria entre escola e família é fundamental para que o aluno consuma mais verduras e frutas e tenha momentos de atividades físicas ao invés de ficar sentado na frente da televisão e do computador.

O papel da escola é desenvolver projetos interdisciplinares em educação alimentar que possibilitem aos alunos se envolvem mais com o conteúdo proposto, participando ativamente da construção dos materiais das oficinas, dos debates e desenvolvendo 
atividades que sejam criativas, interessantes e que propiciem a elas novos conhecimentos e o desenvolvimento de hábitos saudáveis dentro e fora do ambiente escolar.

$\mathrm{Na}$ fase de 4 e 5 anos, ao envolver os alunos nos projetos de educação alimentar, a escola deixará marcas, conhecimentos e lembranças que vão durar por muito tempo. Esse envolvimento dos alunos, da comunidade escolar e dos pais facilita e valoriza as ações do professor. Projetar e desenvolver projetos como os sugeridos neste artigo dá mais trabalho do que explicar o assunto aos alunos, mas as recompensas são maiores se as crianças estiverem mais conscientes da necessidade de uma alimentação saudável.

As crianças nesta idade que adquirem hábitos saudáveis vão necessitar de uma alimentação equilibrada da família e graças a este conhecimento, a sua qualidade de vida será melhorada a curto e longo prazo.

Assim reduzir a obesidade infantil, prevenir futuras doenças do adulto são alguns dos objetivos da educação alimentar que não podem ser ignorados por governos, escolas, famílias e comunidades. Somente trabalhando juntos conseguiremos uma população mais consciente, saudável e feliz.

\section{REFERÊNCIAS}

ABRANTES, Marcelo M. et. al. Prevalência de sobrepeso e obesidade em crianças e adolescentes das regiões Sudeste e Nordeste. Jornal de Pediatria - Vol. 78, № $4,2002$. Disponível em: Acesso em: io jun. 2016. Disponível em https://www.scielo.br. Acesso em 17/02/2022.

ALVES, Luciana et. al. O jogo como recurso de aprendizagem. Rev. Psicopedagogia 2010; 27(83): 282-7. Disponível em http://pepsic.bvsalud.org/pdf/psicoped/v27n83/I3.pdf. Acesso em 17/o2/2022.

BARRETO, Anna Christina do Nascimento Granjeiro et. al. Sobrepeso: uma nova realidade no estado nutricional de pré-escolares escolares de Natal, RN. Rev Assoc Med Bras 2007; 53(4): 311-6. Disponível em https://www.scielo.br. Acesso em 17/o2/2022.

BRASIL. PCN de Saúde. Disponível em http://portal.mec.gov.br. Acesso em 17/o2/2022.

BRASILa. Resolução no 26 de 17 de junho de 2013. Dispõe sobre o atendimento da alimentação escolar aos alunos da educação básica no âmbito do Programa Nacional de Alimentação Escolar - PNAE. Disponível em https://www.fnde.gov.br. Acesso em $17 / 02 / 2022$. 
BRASILb. Referencial Curricular Nacional para Educação Infantil (RCNEI). Brasil. Ministério da Educação e do Desporto. Secretaria de Educação Fundamental. Referencial curricular nacional para a educação infantil / Ministério da Educação e do Desporto, Secretaria de Educação Fundamental. - Brasília: MEC/SEF, 1998. Disponível em http://portal.mec.gov.br/seb/arquivos/pdf/volume2.pdf. Acesso em 17/o2/2022.

BRASILc. Ministério da Saúde. Secretaria de Atenção à Saúde. Guia alimentar para a população brasileira : promovendo a alimentação saudável / Ministério da Saúde, Secretaria de Atenção à Saúde. Brasília: Ministério da Saúde, 2008. 2io p. (Série A. Normas e Manuais Técnicos). Disponível em https://bvsms.saude.gov.br. Acesso em $17 / 02 / 2022$.

Brasil supera baixo peso infantil, mas obesidade preocupa. Disponível em https://memoria.ebc.com.br. Acesso em 17/02/2022.

MINAS GERAIS. Resolução SEE no 1.511, de 26 de fevereiro de 2010. Orienta a aplicação da Lei no $18.372 / 2009$ no âmbito das escolas do sistema estadual de ensino. Disponível em www.educacao.mg.gov.br. Acesso em 17/02/2022.

PRADO, Maria Elisabette Brisola Brito. Pedagogia de projetos: fundamentos e implicações. In: ALMEIDA, Maria Elizabeth Bianconcini de; MORAN, José Manuel (Org.). Integração das tecnologias na educação. Brasília: Ministério da Educação/SEED/TV Escola/Salto para o Futuro, 2005. cap. I, artigo I.I, p. I2-I7. Disponível em http://www.tvebrasil.com.br/salto. Acesso em I7/o2/2022.

SCHMITZ, Bethsáida de Abreu Soares et. al. A escola promovendo hábitos alimentares saudáveis: uma proposta metodológica de capacitação para educadores e donos de cantina escolar. Disponível em http://www.scielo.br. Acesso em i7/02/2022.

YOKOTA, Renata Tiene de Carvalho et. al. Projeto "a escola promovendo hábitos alimentares saudáveis": comparação de duas estratégias de educação nutricional no Distrito Federal, Brasil. Rev. Nutr., Campinas, 23(I):37-47, jan./fev., 2010. Disponível em https://www.scielo.br. Acesso em 17/02/2022. 